\title{
INDUSTRY 4.0 AND BUSINESS PROCESS MANAGEMENT
}

\author{
Jiri TUPA, Frantisek STEINER
}

\begin{abstract}
Production companies are adopting new methods for the improvement of their managing production processes. The cost, quality and time are still key important attributes for process improvement. This is reason why the Business Process Management (BPM) is the core of management in different areas, e.g., quality management, sustainability management. The new technologies based on Internet of Things and Services, SMART solutions, and the concept Industry 4.0 are opening new possibilities of BPM implementation. This theoretical paper deals with a review of new trends in BPM and a presentation of the possibilities of core technologies for Industry 4.0 in phases of BPM applications.
\end{abstract}

Keywords: Business Process Management; improvement; Industry 4.0; performance measurement; Risk Management

\section{INTRODUCTION}

Industry 4.0 is a recent keyword in the manufacturing area. The term 'Industry 4.0 ' has been used mainly by the German government in high-tech strategy. This strategy, with its related current literature, is called Industry 4.0, like '4th Industrial Revolution'.

The increasing number of papers is evidence that this topic is the starting object of research at many research centres and universities. Governments in different countries have adopted concepts that support implementation of the concept Industry 4.0. Concretely the Czech government approved the document 'Initiative Industry 4.0' and allocated support for relevant research projects for examples.

Business Process Management (BPM) is a fundamental theory adopted in large numbers of companies in different industrial sectors. The main ideas are based on the theory of Hammer and Champy [1]. The traditional implementation of this concept is a focus on process analysis, process modelling and optimisation, process automation and measurement of process indicators in relation with performance indicators. The concept BPM has been adopted into international standards, the ISO 9001 for quality management for example.

The concept Industry 4.0 opens new opportunities and research questions. One research question is linked with the future of process management and its implementation for the concept Industry 4.0. This paper tries to find an answer for this research question based on a review of suitable technologies and methods for BPM implementation.

\section{LITERATURE REVIEW}

BPM is term used in many companies. Over the last decade, BPM has played an important role. BPM helps implement methods and tools for process improving. The BPM principles that combine selected findings from management issue and related management science, information technology [2].

Many growing companies implemented this management approach established on Hammer's Business Process Reengineering Concept [1]. The authors follow up Hammer and Champy's ideas in related research and practical papers nowadays. Researchers and practitioners from academy and industry use the term BPM in many different ways.

Prof. August-Wilhelm Scheer mentioned in his book that process management has become an important management instrument in many companies because its practitioners realised that optimising a company's capacity to create value in the form of processes has a direct and immediate effect on the bottom line. [3]

The term BPM has been used in many ways, and several alternatives - from process improvement to intelligent BPM (iBPM) - have been proposed. Some use BPM to refer a general theory to the management of business process change, while others use it more narrowly, to refer to the use of automated software techniques to control the runtime execution of enterprises process. Surveys presented on the state of the BPM market in 2018 presents examples of how organisations use the term BPM for example [4].

Different articles in international conference proceedings and books deal with BPM issues [5]. The high number of citations for term business process management (BPM) seems to prove that BPM is an important field of recent research activities. The BPM issue is the point of research focused on technological or methodological solutions of problems related with BPM implementation [6].

Nowadays, the issue focused on BPM is an integrated and continuous process, which deals equally with technological and organisational considerations. It is important to understand that BPM itself represents a process. It is a process consisting of the phases of strategy definition, process description, process implementation and process execution. The whole implementation of BPM includes these important activities:

- Analysis of processes

- Definition of structure between processes

- Choice of management method

- Modelling and optimising of processes

- Determination of performance measurement and diagnostics system. 
The main purpose of this process implementation is to improve an organisation's effectiveness in achieving its defined objectives.

The benefits of Business Process Management are to improve the alignment of all aspects of an organisation with internal rules and transparency, to increase customer satisfactory, to promote business efficiency, to maximally exploit employee potential, to improve product quality, and to reduce costs.

Examples of BPM are present in areas where effective progress has been achieved, including, as presented in [5]:

- The systematic validation of business process models before implementing them via information system, to avoid potentially costly mistakes at run on-time.

- The automatic generate of configurable process models from a collection of process model variants, used to guide analysts when selecting the right configuration.

- The complex identification of process behaviours based on scientific insights provided by the workflow patterns initiative.

- The implementation of processes on-the-fly and the evaluation of the impact of their changes, in order to react to (unexpected) exceptions.

- The automatic execution of business process models based on strictly defined semantics, through a variety of information systems supported BPM.

- The automatic finding of process models from raw event data stored in databases of information systems.

\subsection{Industry 4.0}

The keyword Industry 4.0 is very often cited in recent journal and conference papers. Different authors present this phenomenon like the fourth industrial revolution. Industry 4.0 is a recent trend in the manufacturing world. The term 'Industry $4.0^{\prime}$ ' has been used mainly by the German government in the high-tech-strategy. Historical and current phases are presented in Tab. 1. The table mentions key inventions and technology that are typical for these periods.

Table 1 Core technologies of Industry 4.0 - adopted from [10]

\begin{tabular}{|c|c|c|c|}
\hline & $\begin{array}{c}\text { Phase of Industrial } \\
\text { Revolution }\end{array}$ & Key Invention & $\begin{array}{c}\text { Technologies and } \\
\text { Capabilities }\end{array}$ \\
\hline \multirow{3}{*}{$\stackrel{2}{0}$} & Industry 1.0 & Steam machine & $\begin{array}{l}\text { Introduction of } \\
\text { mechanical production } \\
\text { facilities with the help } \\
\text { of water and steam } \\
\text { power. }\end{array}$ \\
\hline & Industry 2.0 & $\begin{array}{l}\text { Electrical } \\
\text { machines and } \\
\text { drivers }\end{array}$ & $\begin{array}{l}\text { Introduction of the } \\
\text { division of labour and } \\
\text { mass production with } \\
\text { the help of electricity } \\
\text { energy. }\end{array}$ \\
\hline & Industry 3.0 & $\begin{array}{l}\text { Computer } \\
\text { (programmable } \\
\text { logic controller) } \\
\end{array}$ & $\begin{array}{l}\text { Use of electronic and } \\
\text { IT systems that further } \\
\text { automate production. }\end{array}$ \\
\hline 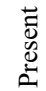 & Industry 4.0 & Internet & $\begin{array}{l}\text { Use of cyber-physical } \\
\text { system. }\end{array}$ \\
\hline
\end{tabular}

The main idea of Industry 4.0 is the emergence of "smart factories", which will be connected to the production facilities' cyber-physical systems called CPS.

Developing the Internet of Things, the Internet of Services, and the Internet of People will help to make connections between human-machine, human-human or machine-machine, and with it also an enormous amount of data is obtained. For this reason, it will be useful to analyse a large amount of data (Big Data). It be able to predict possible faults and making decision on-line to the changed conditions [7] and [8], for example.

\subsection{Policies to Support Industry 4.0 Developments}

In its Industrial Policy Papers of 2012, the European Commission defined six basic priorities, three of which thematically cover areas related to the Industry 4.0 concept. Specifically, these include advanced manufacturing, key enabling technologies (e.g. batteries, smart materials and high-performance manufacturing processes), and smart networks and digital infrastructures (where infrastructure and networking are seen as crucial). [10].

Subsequently, in 2013, the Commission appointed a Working Group on Modern Net Production and in 2014 a Strategic Policy Forum on Digital Business to Digital Transform the European Industry and Enterprises. The Forum recommended setting national targets, setting up centers of excellence, strengthening standardization, ensuring funding and encouraging the development of digital skills. European authorities also called for a "observatory" for the digital transition and increasing political awareness about digital issues and policy implications. [10]

In the 2014 declaration "For the European Industrial Renaissance", the European Commission stressed that digital technologies (including cloud computing, new industrial Internet applications, large data, smart factories, robotics and $3 \mathrm{D}$ printing) are important to boosting European productivity and innovation in companies through new business models and developing new services and products. [11]

The issue of digital transformation of Europe is one of the most important key actions of the EU. This business and trade transformation is a challenge for Europe and represents a huge growth potential for innovation. Traditional industries in Europe can build on their strengths in advanced digital technologies. This will open up these sectors to gain market share in the emerging markets for products and services of the future.

\subsection{Digital Transformation}

Digital transformation is defined in the literature as the integration of advanced technologies with physical and digital systems, most innovative business models and new processes, and the development of SMART products and services. [12]

The published Digital Transformation Monitor is the one of the EU action publication. The monitor gives the opportunity to monitor statistical and factual evidence of the pace of digital transformation in specific sectors and in all 
EU countries. It tries to identify key trends in digital transformation and to measure progress made at national and sector-specific levels. It also supports policy development and analyses major national policy initiatives. [12]

On the other hand, measurement of digital performance and tracking the development EU member states in digital competitiveness are made by the Digital Economy and Society Index (DESI). The DESI overall index is calculated as the weighted average of the five main DESI dimensions with the weights selected by the user: 1 Connectivity, 2 Human Capital, 3 Use of Internet, 4 Integration of Digital Technology, and 5 Digital Public Services. [13]

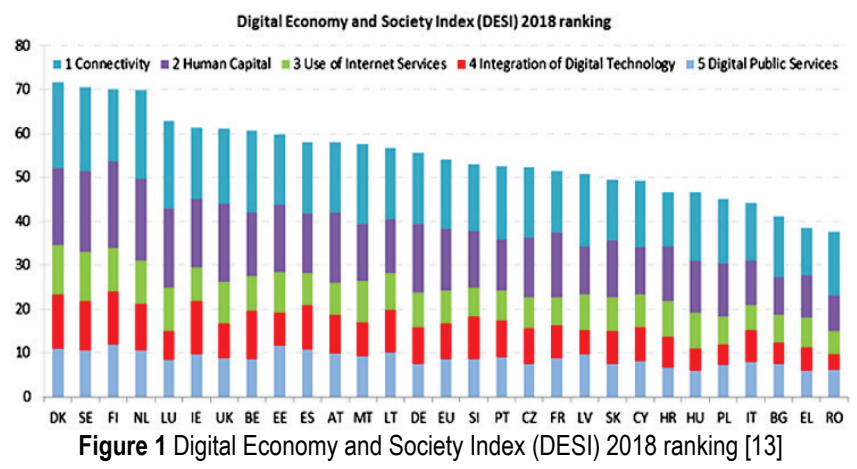

Based on the published assessment in 2018, it is clear that Denmark, Sweden, Finland and the Netherlands are among the most advanced digital economies in the EU, followed by Luxembourg, Ireland, the United Kingdom, Belgium and Estonia (Fig. 1). On the other hand, Romania, Greece and Italy have the lowest scores on DESI. This evaluation can be used very well to compare EU Member States and evaluate their preparation for the implementation of the Industry 4.0 concept. Finally, based on this state of art, we can conclude that the concept Industry 4.0 opens a new dimension of management science.

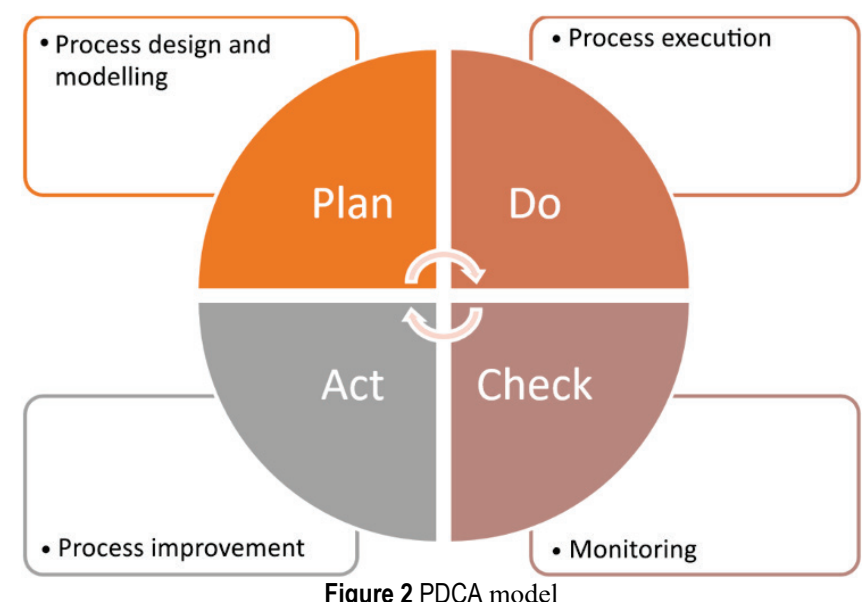

\section{INDUSTRY 4.0 AND BUSINESS PROCESS MANAGEMENT}

The number of automated process will be increasing, and due to this fact, traditional management tools and technique should be revised. Business process management is one of them. Based on this fact, we have tried to answer the research question - What is role of process management for Industry 4.0 ? - in this paper. The revision of the BPM approach in context of Industry 4.0 has been examined through the Deming PDCA cycle because this cycle describes phases of process BPM implementation. [14]. Fig. 2 presents activities for implementing each phase of PDCA.

\subsection{Process Design and Modelling}

Process design and modelling are the initial activities of process management implementation. The aim of this activity is to find and describe existing processes and suggest a "to be" state. Areas of focus include process representation, attributes, such as inputs, outputs, resources, and related documentation.

Process modelling is a useful tool to capture, formalise and structure the knowledge of business processes. The models can be deterministic, stochastic, uncertain but structured, or uncertain but imperfectly structured. Modelling tools can be categorised into business process chain-based type such as Petri net, IDEFO, IDEF3, BPMN 2.0, ARIS-eEPC, etc.; formal description type such as WPDL, XML, process algebra, predicative logic, etc.; and object-oriented type such as IDEF4 and UML. The overall model is analysed on the individual models. Models would have to contain all process attributes and static and dynamic parameters such as process time, process threats, cost, etc.

New technologies of Industry 4.0 have new role of process design and process modelling. The new role is related with process digitalisation. The term of digitalisation of processes is related with smart factory or digital supply chain network. In the context of process management, digital transformation refers to transforming the business operations, services and models. Digital transformation covers all process in the companies, and the aim is to build a digital model of enterprise with the digitised process attributes (input, output, sources and indicators). The companies should determine rules, methods and standards for process transformation. The result of this step is a digital model of enterprise.

This model contains:

- Relationship between cyber and physical layer

- Description of the main processes (processes that create added value)

- Definition of support processes and autonomous control processes.

\subsection{Process Execution}

Execution means that instances of a process are performed or enacted, which may include automated aspects. Automation of business processes is based on using the Business Process Execution Language (BPEL). The BPEL language is perfectly suited to a clear description of the processes by which processes can be then mechanically exercised. BPEL enables organisations to automate their processes (so-called service orchestration). The BPEL language allows description of the conduct and behaviour of 
business processes as a sequence of activities, including their branches, which are engaged in the process, while these activities are represented by web services (WS) [2].

Business process execution in terms of Industry 4.0 is related with the digital factory and application of Cyber Physical System (CPS). The rules and process model can be used for the definition of elementary relationships in CPS. The cyber level of CPS enables to simulate the process using digital twins and makes an environment for process execution [15].

The CPS implements these elements:

- Data acquisition and data processing

- Machine-to-machine communication

- Human-machine interaction.

\subsection{Process Monitoring}

The main principles of a process monitoring system are described by many authors, and a lot of them discuss the phrase 'process performance measurement'. Process performance measurement is the combination of processes, methodologies, metrics and technologies to measure, monitor and manage the performance of the process. To measure and execute process performance, we can use different Key Performance Indicators (KPIs).

These KPIs, also known as process performance indicators, are indicators that can be unambiguously assigned and used for a given process, provided that data is available to calculate these performance indicators [16]. Basic performance parameters are defined, which are time, quality and cost. Specifically, for example, we can measure implementation costs, resource use and waste; time using cycle time, waiting time or no value added time; and quality through customer satisfaction and error rates. Some KPIs can be measured relatively easily, such as cycle time.

The implementation of IoT or Internet of Services, Process and People (Internet of Everthing) and related technologies helps to implement a system for automated and real-time process monitoring. These technologies help to display the state of processes. The automated system of measurement enables data storage in data warehouses, and we are speaking about the analysis of Big Data.

Big data analysis can be defined as the process of examining large and diverse data, identifying hidden patterns, unknown correlations, trends, and other useful information that can help organizations improve their decision-making processes at all levels of management.

Data can be used for:

- Dynamic organisational analysis

- Process optimization

- Right-time monitoring

- Process mining for automated weak point analysis

- Process simulation.

The role of process monitoring is a key process in the CPS. Real-time automated processes can be monitored online with the application of a system based on IoT and IoE. The paper [17] presents a model for performance process measurement based on an implementation of IoT technologies. This model is based on the standards ISA-95 and ISO 22400.

The standards formally describe how a manufacturing process can be formalised and the steps for set-up of the suitable performance indicators. The ISO 22400 standard is a four-part standards; two parts are under development, and two parts are under consideration. The standard ISO 240002 defines thirty-four KPIs (key performance indicators) and their equations. Fig. 3, adopted from [17], presents the IoTbased production performance model developed in accordance with ISO 22400 and ISA 95.

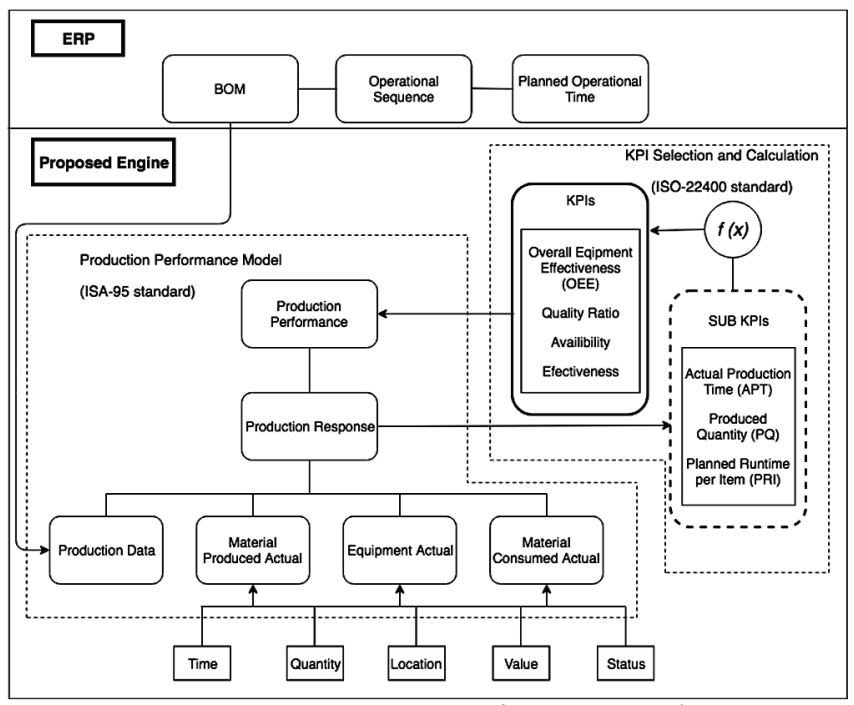

Figure 3 loT-based production performance model [17]

The model presents data transfer between the production line and the Manufacturing Execution System. Based on the IoT functionality, process data that include information about the time, location, cost, quantity and status can be acquired from the product. The stored data are then adjusted with the production performance model, which includes of material consumed actual, of the equipment actual, material produced actual and of three subparts for example.

IoT data cannot be used directly for all KPIs; then you need to define additional databases for additional data. For example, these are production data, which are ordered according to the sequence of processes, e.g. with the planned process time, the BOM. Production data is obtained from ERP and includes structured information on the production plan. Using the planned and actual data, the above sections classify IoT data based on their description to provide a toplevel source for calculating sub-KPIs. The production reaction then uses the sub-KPI to calculate the final KPIs.

\subsection{Process Improvement}

Process improvement is the last, important phase of business process management. The aim is continual improvement of business processes based on monitoring and data collection. Especially in the context of digital processes, the identification of existing pain points can be realised through the performance of continuous software tests. 
Another definition explains process improvement as the proactive task of identifying, analysing and improving upon existing business processes within an organisation for optimisation and meeting new quotas or standards of quality. The companies collect data, not only from manufacturing processes, but from all processes during the product life cycle.

The companies use several methodologies, like Six Sigma, Centric leverages DMAIC (Define, Measure, Analyse, Improve, Control), Lean principles, etc. New possibilities of technologies of Industry 4.0 can effectively support the implementation of the mentioned methodologies. The selection of a continuous improvement methodology depends on the overall strategy. The demonstration of Lean principles and other improvement methodology implementations have been presented in papers [18].

\subsection{Discussion}

The implementation of Business Process Management for the concept Industry 4.0 is a new topic, which is not exactly mentioned in the literature. The SWOT analysis (Tab. 2 ) was used for a summary of the strength and weakness and the opportunities and threats for a company based on previous subchapters (3.1-3.4) and related literature.

\section{Table 2 SWOT analysis}

\begin{tabular}{|c|c|}
\hline $\begin{array}{l}\text { Strengths: } \\
\text { - Theoretical background } \\
\text { - Knowledge from Business } \\
\text { Process Management } \\
\text { - Existing standards for process } \\
\text { digitalisation } \\
\text { - Using Big Data for process } \\
\text { monitoring, controlling and } \\
\text { performance management }\end{array}$ & $\begin{array}{l}\text { Weaknesses } \\
\text { - } \text { Cost for implementation of CPS } \\
\text { or IoT } \\
\text { - Training of staff and personal } \\
\text { - Time to implementation } \\
\text { - No existing related suitable } \\
\text { methods and tools for process } \\
\text { optimisation }\end{array}$ \\
\hline $\begin{array}{l}\text { Opportunities: } \\
\text { - Develop new lead markets for } \\
\text { products and services } \\
\text { - Open a new challenge for } \\
\text { markets } \\
\text { - Development of effective supply } \\
\text { chains }\end{array}$ & $\begin{array}{l}\text { Threats } \\
\text { - Cybersecurity and IT criminality } \\
\text { - Lack of IPR protection } \\
\text { - Vulnerability to volatility of } \\
\text { economy }\end{array}$ \\
\hline
\end{tabular}

As mentioned, the important part of business process management is to define the suitable architecture and rules which help to implement the concept Industry 4.0.

\section{ARCHITECTURE AND RULES FOR BUSINESS PROCESS MANAGEMENT IMPLEMENTATION}

Architecture and rules provide a common structure and language for the uniform description and specification of system architectures. The concept Industry 4.0 uses a reference architecture model. Reference Architectural Model Industry 4.0, abbreviated RAMI 4.0 (Fig. 4), consists of a three-dimensional coordinate system that describes all crucial aspects of Industry 4.0. Indicated on the right horizontal axis are hierarchy levels from IEC 62264, the international standards series for enterprise IT and control systems. These hierarchy levels represent the different functionalities within factories or facilities. The left horizontal axis represents the life cycle of facilities and products, based on IEC 62890 for life-cycle management. [19]

The six layers on the vertical axis serve to describe the decomposition of a machine into its properties structured layer by layer, i.e. the virtual mapping of a machine. The RAMI architecture links to other important standards for concept Industry 4.0 implementation.

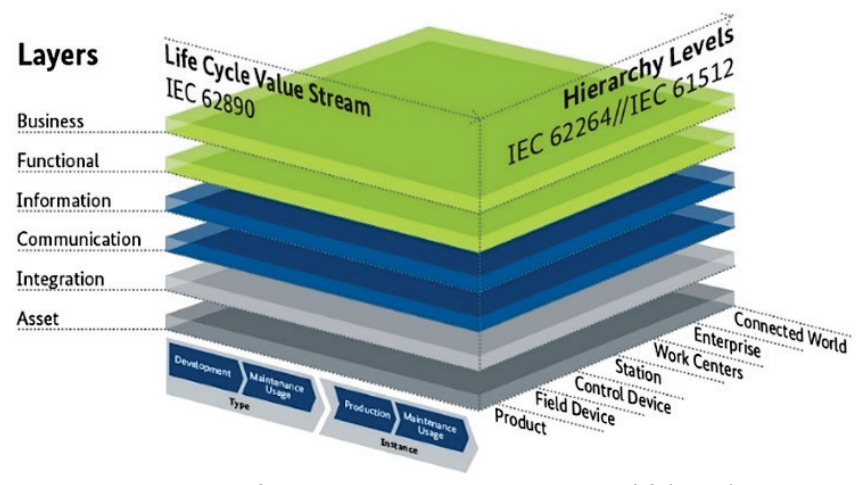

Figure 4 Reference Architectural Model Industry 4.0 (RAMI)

The Tab. 3 presents areas of implementation and titles of selected standards [20]. The architecture RAMI and related standards help to analyse and describe basic processes at the smart factory and all processes related with digital supply chain. All the business processes can be adopted in this model, and this model can set up business rules and architecture for a smart factory.

Table 3 Standards for Industry 4.0 [20]

\begin{tabular}{|l|l|}
\hline Area of implementation & \multicolumn{1}{|c|}{ Title of standard } \\
\hline Security & $\begin{array}{l}\text { Information Security Management Systems, } \\
\text { Network and System Security }\end{array}$ \\
\hline Safety & Functional Safety, Safety of machinery \\
\hline Digital factory & Reference model for the digital factory \\
\hline Information layers & Classification and product description \\
\hline Configuration & $\begin{array}{l}\text { Function blocks for process } \\
\text { control/electronic device description } \\
\text { language } \\
\text { Field device tool (FDT) interface } \\
\text { specification }\end{array}$ \\
\hline Hierarchy level & $\begin{array}{l}\text { Batch control, Enterprise-control system } \\
\text { integration }\end{array}$ \\
\hline Communication layer cycle & $\begin{array}{l}\text { Industrial communication network, } \\
\text { Machine-to-machine communication }\end{array}$ \\
\hline Condition & Life-cycle status \\
\hline Energy & Condition monitoring \\
\hline Engineering & Energy efficiency \\
\hline Semantics & $\begin{array}{l}\text { Industrial automation systems and } \\
\text { integration, Automation Markup Language }\end{array}$ \\
\hline Management & W3C Semantic Web stack \\
\hline & $\begin{array}{l}\text { Quality management, Risk Management, } \\
\text { Key Performance Indicators for } \\
\text { Manufacturing Operations }\end{array}$ \\
\hline
\end{tabular}

\section{RISK MANAGEMENT}

Risk management is an important part in the business process management area nowadays. Enterprises try to implement risk management procedures as part of the 
management process. They try to implement management system with process, quality and risk management for performance measurement. This way is also recommended in ISO standards for quality management system described in the new revision of ISO 9000 standards in year 2015.

The task of the risk management is a systematic approach to assessing and acting on risks in order to ensure that organisational objectives are achieved. The concept Industry 4.0 opens a new challenge for risk management nowadays.

The mentioned concept Industry 4.0 can generated new kinds of risks in related area because of the increase of threats and vulnerability. The networking of cyber-space, advanced manufacturing technologies and elements, and implementation of services outsourcing is the main factor increasing the vulnerability. An identification of new categories of risks is presented in Tab. 4 .

Table 4 Identification of new risks adopted from [21]

\begin{tabular}{|l|l|}
\hline \multicolumn{1}{|c|}{$\begin{array}{c}\text { Categories of manufacturing } \\
\text { risks }\end{array}$} & \multicolumn{1}{c|}{ Risks } \\
\hline Maintenance & $\begin{array}{l}\text { Problem with availability and } \\
\text { integrity of data for maintenance. }\end{array}$ \\
\hline $\begin{array}{l}\text { Used manufacturing methods and } \\
\text { tools }\end{array}$ & Errors in data processing. \\
\hline $\begin{array}{l}\text { Manufacturing process } \\
\text { management }\end{array}$ & $\begin{array}{l}\text { Information risk associated with } \\
\text { data losses, break of integrity and } \\
\text { available information. }\end{array}$ \\
\hline Human sources & Low number of qualified workers \\
\hline Machine environments & $\begin{array}{l}\text { Attacks from Internet network, } \\
\text { problems related to electromagnetic } \\
\text { compatibility and electromagnetic } \\
\text { emissions affect manufacturing } \\
\text { machines. }\end{array}$ \\
\hline $\begin{array}{l}\text { Machines and manufacturing } \\
\text { technologies }\end{array}$ & $\begin{array}{l}\text { Sensitivity and vulnerability of } \\
\text { data-problem related to cyber- } \\
\text { attacks. }\end{array}$ \\
\hline
\end{tabular}

This identification has recommend an important steps for risk management implementation.

The results of our finding present that the most of common risk factors in the manufacturing area can be associated to information security. A discussion about a new term - Information, Communication and Manufacturing Technologies (ICMT) - which reflects the requirements of Industry 4.0 can be started. The reason is that manufacturing infrastructure autonomous intelligent manufacturing system, machines and robots communicate with each other, which should be included under the umbrella of ICT. The important question is how to protect the ICMT against cyber-attacks, loss of data integrity or problems with availability of information. An implementation of information security management systems can answer this question.

\section{CONCLUSION}

The aim of this theoretical contribution is to summarise the key elements of Business Process Management for the adoption of the concept Industry 4.0. The concept Industry 4.0 opens new challenges for process management implementation nowadays. The technologies based on CPS, IoT, Digital Factory etc. help to improve processes based on effective process measurement, simulation and application of predictive models.

The implementation of process management has been demonstrated by using the PDCA cycle. The core of this concept implementation is based on different rules and standards integrated in the RAMI model.

The implementation of BPM is associated with the risk management area. In this point of view, the concept Industry 4.0 can generate new risks in the manufacturing area. These risks are associated with cyber-attacks, for example, the loss of data integrity etc. The identification of these new risks was described in Chapter 4, and the chapter answered the first research question: What new kinds of risks are associated with manufacturing concept Industry 4.0? In the face of new threats, companies should try to implement an information security management system into the manufacturing area

We conclude that Business Process Management is the perspective discipline nowadays, and with the concept Industry 4.0, new challenges for its successful implementation are opened.

\section{Acknowledgements}

This research has been supported by the Ministry of Education, Youth and Sports of the Czech Republic under the RICE - New Technologies and Concepts for Smart Industrial Systems, project No. LO1607 and by the Technology Agency of the Czech Republic under the project Software platform to accelerate the implementation of management systems and process automation — project No. TH02010577.

\section{REFERENCES}

[1] Hammer, M. \& Champy, J. (1993). Business process reengineering. London: Nicholas Brealey.

[2] Weske, M. (2012). Business process management: Concepts, languages, architectures. Berlin: Springer. https://doi.org/10.1007/978-3-642-28616-2

[3] Scheer, A., Abolhassan, F., Jost, W., \& Kirchmer, M. (Eds.). (2002). Business process excellence. Berlin: Springer. https://doi.org/10.1007/978-3-540-24705-0

[4] Harmon, P. (2018). The state of business process management - 2018. BPTrends.

[5] van der Aalst, W. M. P., La Rosa, M., \& Santoro, F. M. (2016). Business process management. Business \& Information Systems Engineering, 58(1), 1-6. https://doi.org/10.1007/s12599-015-0409-x

[6] Jeston, J. \& Nelis, J. (2008). Business process management. Oxford: Butterworth-Heinemann. https://doi.org/10.4324/9780080492520

[7] Lasi, H., Fettke, P., Kemper, H. G., Feld, T., \& Hoffmann, M. (2014) Industry 4.0. Business \& Information Systems Engineering, 6(4), 239-242. https://doi.org/10.1007/s12599-014-0334-4

[8] Richert, A., Shehadeh, M., Plumanns, L., Gros, K., Schuster, K., \& Jeschke, S. (2016). Educating engineers for industry 4.0: Virtual worlds and human-robot-teams: Empirical studies towards a new educational age. In IEEE Global Engineering Education Conference (EDUCON), 142-149. https://doi.org/10.1109/EDUCON.2016.7474545

[9] Lopes de Sousa Jabbour, A. B., Jabbour, C. J. C., Godinho 
Filho, M., \& Roubaud, D. (2018). Industry 4.0 and the circular economy: A proposed research agenda and original roadmap for sustainable operations. Annals of Operations Research, 270, 273-286. https://doi.org/10.1007/s10479-018-2772-8

[10] Davies, R. (2015) Industry 4.0. Digitalisation for productivity and growth. European Parliamentary Research Service.

[11] European Commission (2014). Towards an Industrial Renaissance. Retrieved from https://ec.europa.eu/growth/ industry/policy/renaissance_en

[12] European Commission (2017). Digital transformation. Retrieved from https://ec.europa.eu/growth/industry/policy/ digital-transformation_en

[13] European Commission (2019). The Digital Economy and Society Index (DESI). Retrieved from https://ec.europa.eu/ digital-single-market/en/desi

[14] Aziz, N. A. A., Manab, N. A., \& Othman, S. N. (2016). Critical success factors of sustainability risk management (SRM) practices in Malaysian environmentally sensitive industries. Procedia - Social and Behavioral Sciences, 219, 4-11. https://doi.org/10.1016/j.sbspro.2016.04.025

[15] Prause, G. (2015). Sustainable business models and structures for Industry 4.0. Journal of Security \& Sustainability Issues, 5(2), 159-169. https://doi.org/10.9770/jssi.2015.5.2(3)

[16] Gündüz, M. (2015). Value stream performance measurement in lean manufacturing business. International Business and Management, 10(3), 40-47.

[17] Hwang, G., Lee, J., Park, J., \& Chang, T.-W. (2017). Developing performance measurement system for Internet of Things and smart factory environment. International Journal of Production Research, 55(9), 2590-2602. https://doi.org/10.1080/00207543.2016.1245883

[18] Wagner, T., Herrmann, C., \& Thiede, S. (2017). Industry 4.0 impacts on lean production systems. Procedia CIRP, 63, 125131. https://doi.org/10.1016/j.procir.2017.02.041

[19] Schweichhart, K. (2016). Reference Architectural Model Industrie 4.0. Berlin: Federal Ministry for Economic Affairs and Energy.

[20] Enterprise Information Systems (2017). Standards for Industry 4.0. [Online]. Retrieved from http://i40.semanticinteroperability.org/

[21] Tupa, J., Simota, J., \& Steiner, F. (2017). Aspects of Risk Management Implementation for Industry 4.0 in Standards for Industry 4.0. Procedia Manufacturing, 11(2017), 1223-1230. https://doi.org/10.1016/j.promfg.2017.07.248

\section{Authors' contacts:}

Jiri TUPA, Corresponding author University of West Bohemia in Pilsen

Faculty of Electrical Engineering

Univerzitni 8, 30614 Pilsen, Czech Republic

tupa@ket.zcu.cz

Frantisek STEINER

University of West Bohemia in Pilsen

Faculty of Electrical Engineering

Univerzitni 8, 30614 Pilsen, Czech Republic 